\title{
The Mashups of YouTube
}

\author{
Thomas Mosebo Simonsen
}

\begin{abstract}
This article focuses on YouTube mashups and how we can understand them as a specific subgenre on YouTube. The Mashups are analysed as audiovisual recontextualizations that are given new meaning, e.g., via collaborative social communities or for individual promotional purposes. This is elaborated on throughout a discussion on Mashups as a mode of everyday bricolages, which are moreover discussed through a theoretical approach to Mashups as exponents of what has been called "Vernacular Creativity". The article also argues that the novelty of Mashups is not be found in its formal characteristic, but rather in its social and communicative abilities within the YouTube community. This leads to the article's overall argument that the main characteristic of the YouTube Mashup can be explained in terms of connectivity. It is argued that Mashups reveal a double articulation of connectivity; one that involves the social mechanisms of the Mashups, and another mode, which concerns the explicit embedding of structural connectivity that accentuates the medium-specific infrastructure of YouTube. This double articulation of connectivity is furthermore elaborated on by including Grusin and Bolter's concept of remediation.

Methodologically, the article draws on empirical observations and examples of Mashups are included to demonstrate the article's main arguments.
\end{abstract}

Keywords: YouTube, mashups, connectivity, remediation, social media, vernacular creativity

\section{Introduction}

On YouTube, a culture of audiovisual expressions has emerged that I will characterize here as the Mashup culture of YouTube. Mashups are videos that have their origin in the music sampling culture and are considered recontexualizations of already existing materials (cf. Katz 2010: 174). The Mashups have been extended to YouTube and include the recontextualization of different types of mainly user-generated content (UGC) or as stated by William Urrichio: [Mashups are] "(...) individual videos that make use of disparately sourced sounds and images remixed into a new composite" (2009: 24).

We are witnessing, on YouTube, the growing phenomenon of Mashups, in which already existing videos are recontexualized and provided with new meaning. An important aspect of the emergence of Mashups is YouTube's status as the world's largest online media archive, where consumption of videos as of January 2012 exceeded 4 billion a day and where 60 hours of content is uploaded every minute ${ }^{1}$. YouTube seems to have embraced the notion of Mashups as a somewhat intrinsic exploration in terms of its status as a media archive, making it the perfect breeding ground for creating new content, i.e. mixing already existing and freely accessible content. This includes the video The Dou- 
ble Rainbow Song, which is a music video in which we see a home video recording of a literal double rainbow, underlined by the singer, repeating the words: "Double Rainbow".

The music video is a Mashup, a remix of a home movie recorded with what appears to be a mobile phone camera with the creator's added voice over, which through the use of a phase vocoder has been turned into a song. The original video is a home movie made by a camper, who is on a trip in the mountains when he observes a double rainbow in the sky. His emotional reaction seems somewhat exaggerated and probably influenced by drugs. The original video went viral when a talk show host posted a tweet and a link to the video in July $2010^{2}$, and it quickly became one of the most shared videos during the summer of 2010 .

A few days later, the YouTube channel schmoyoho uploaded a remixed version of the video, named The Double Rainbow Song. As of August 2012, The Double Rainbow Song received more than 30 million views on YouTube, 95,000 comments and 130 video responses. Thus the question remains: How has this video managed to become so popular on YouTube? The present article will set out to investigate the principal characteristics of the YouTube Mashups, where one argument is that the success of The Double Rainbow Song can be found in its ability to communicate a shared reference of popular culture that is specifically consumed and understood by YouTube's widespread community and in that sense demonstrates what we can regard as a mode of social connectivity.

Following the notion of connectivity, the article seeks to identity the Mashup genre as a specific mode of audiovisual communication that relies on connectivity in a shared community of popular culture that vacillates between a participatory culture and individual artistic expression. It is, however, simultaneously a mode of communication that is essentially intertwined with YouTube's infrastructure, thus rendering the Mashups a matter of structural connectivity.

In order to elaborate on this double notion of connectivity, the article will further apply Bolter and Grusin's concept of "remediation" (1999), as it argues that a central aspect of connectivity is founded on the social features of the site, but at the same time as a manifestation of the Internet's contemporary infrastructure. This aspect is also implied in Manovich's (2007) understanding of Mashups as the remix of data (e.g., in terms of syndicates), which is rendered in the embedding of YouTube content via links to other platforms, and explicitly present in the YouTube Mashups as an audiovisual mode of communication. The article thus argues that Mashups can be regarded as a double articulation of connectivity, i.e. socialization, and simultaneously through YouTube's infrastructure in terms of links and metadata.

The starting point of the present article is to identify the Mashups on YouTube and place them in a historical context in terms of style and structure that bridges the present amateur style of YouTube with the collage and bricolage style as presented by, e.g., Lévi Strauss and to describe what has been called a mode of Vernacular Creativity (cf. Burgess and Green 2009).

In order to comprehend the YouTube Mashups, the article will initially present its methodological framework. It draws on an empirical study based on a content sample of some of the most popular YouTube videos, from which selective cases will be presented to describe the scope of the Mashups. 


\section{Methodological Framework}

The videos included in the analyses presented here are drawn from an empirical study of YouTube content. Nine-hundred videos were observed during the summer of 2010, gathered from the available browsing categories of YouTube's most popular content ("Most Viewed" (n=300), "Most Discussed" $(n=300)$ and "Top-Rated" $(n=300))$. Through a coding process, Mashup videos were identified as a specific type of UGC. UGC, in relation to YouTube, refers to audiovisual videos that are created by ordinary creators who produce content that is publicity available and has not been previously distributed on other media platforms. The differences between UGC and non-UGC, besides distribution forms, can also be determined through agency and the usage of medium-specific affordances.

Mashups can be considered a specific type of UGC that favours the collage style and remix style when incorporating different types of content. As communicative audiovisual texts, the Mashups are different from other types of UGC that tends to favour first-person presentations of the creator (e.g., video blogging), whereas the creator of a Mashup is rarely visually present.

I have defined an overall distinction between four types of content, and between UGC and non-UGC. There are two types of non-UGC: music videos (MV) and television highlights (TVH), which involve cross-media content already distributed on other platforms outside the perimeters of YouTube. There are also two types of UGC: regular UGC and Mashups. Although a Mashup is also UGC and could be considered a subcategory to UGC, I have nonetheless chosen to make an overall distinction based on the Mashup's characteristic of explicitly re-combining audiovisual content into a new video.

After excluding duplicates and non-identifiable content, a sample of 737 videos remains.

\section{Figure 1.}

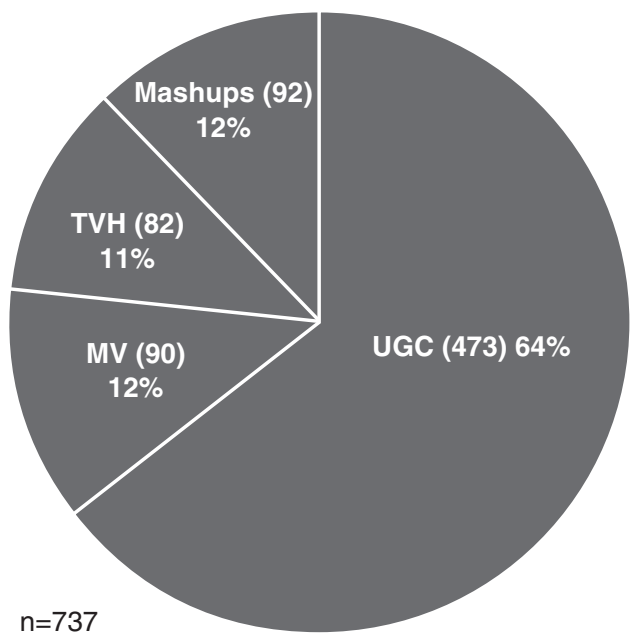

Overall, the distinction between UGC and non-UGC, and furthermore between UGC and Mashups, results in a sample of 92 videos that will henceforth be referred to as Mashups. The sample is by no means an extensive representation of YouTube's content, but it provides an indication of the Mashup as a specific type of content that, in this 
sample, is just as widespread as MV and TVH. The sample thus enables identification of the different types of Mashups.

The creativity of the everyday is thus founded in social principles rather than traditional modes of aesthetics, and in that sense the Mashup emphasizes social connectivity although not excluding individual self-expression.

\section{The Cultural Context of Mashups}

Throughout the $20^{\text {th }}$ century, there have been several examples of techniques resembling the creation of Mashups, e.g., in the aesthetic practices of cubist artists such as Picasso and Braque or the principle of the "Ready Mades" (cf. Hebdige 1979), as well as the editorial techniques of Vertov in the early 1920s (cf. Michelson 1984). What distinguishes Mashups from a painting by Picasso or a film by Vertov is the overall context within which the content is consumed. While cubist paintings are regarded as elitist art, Mashups are a manifestation of a mass consumption of popular culture, produced and consumed within a folkloric context that involves the potentiality of user participation between creators and viewers, and collective creativity in a shared YouTube community. The YouTube community is not officially defined, but frequently referred to by many YouTubers. It can be regarded as a shared social space of knowledge in which YouTube is understood as a platform and its own popular culture (see also Strangelove 2010: 103 pp.).

In his manifesto KinoEye, Vertov emphasized the existence of a latent creativity in regard to people's everyday creativity:

Everyone has something of the poet, artist, musician (...) The million part of each man's inventiveness in his everyday work contains an element of art (Michelson 1984: 162).

Although written in 1924 and with a political tone (being propaganda), Vertov describes a principle that is similar to how we can understand the involvement of Mashups in everydayness. This is furthermore related to accessibility as perhaps the most significant characteristic of the emergence of a Mashup culture. On YouTube, everybody has access to everything, which makes creating content available for everybody with a camera and a reason to produce videos.

Accessibility to endless amounts of content has also enabled the process of editing, and recombining different texts within the Mashups is a process similar to what LéviStrauss called "bricolage". Bricolage describes the ability to make creative use of the materials made available from "whatever is at hand", and it is a "raw" or "naïve" art (1962:17). Drawing on Lévi-Strauss, Terence Hawkes describes the bricolage as:

(...) the means by which the non-literate, non-technical mind of so-called 'primitive' man responds to the world around him. The process involves a 'science of the concrete' (as opposed to our 'civilized' science of the 'abstract') (2003: 51).

The bricolage is concerned with a "science of the concrete". The concrete is the cultural texts of everyday life that are given new meaning in the bricolage. Mashups are styles of bricolage that thus far have been distributed on YouTube in a context primarily associated with light entertainment (cf. Burgess and Green 2009) or even the mundane and tasteless (cf. Keen 2007). 
The bricolage style of the Mashup moreover articulates the characteristic of a shared culture that is demonstrated in the Mashup's inherent reliance on intertextuality. The integration of intertextuality is related to a shared popular culture from which many Mashups are created and to the meaning generated through intertextual references. This is also parallel to Paul Miller's description of the "Remix-culture" emerging during the 1980 s, where both remix and Mashups resemble a "shared folk culture, where creative expression is the property of the community" (Miller et al. 2008: 101). The effect of this shared culture and its collective reference points, according to Miller, leads to an intertextual space of references that requires pre-existing and experienced cultural knowledge in order to participate in the community.

In Capturing Sound, Mark Katz has similarly described the musical Mashup as an act of transformation, while simultaneously emphasizing the social act of recognition:

The transformative power of recontextualization is particularly clear in the Mashup, the whole purpose of which is to generate new mood and meaning

(...) while leaving the source materials recognizable (2010: 174).

This social aspect based on recognition also seems to be a fundamental element of the YouTube Mashup that in most cases recontextualizes already popular content. However, in contrast to both the art of bricolage exhibited at museums and the musical remix culture, the YouTube Mashups as audiovisual expressions cannot easily be placed within the traditional distinction between high/low or good/bad art, as they consist of a melting pot of fully accessible content that cannot be defined in a clear-cut conventional system of cultural categorization.

\section{Mashups as Vernacular Culture}

Jean Burgess applies the term "Vernacular Creativity" to mean a depiction of how creative practices have changed with the emergence of new media and how users increasingly participate in the public exchange of content, leading to a change in consumption. Vernacular Creativity is thus " (...) a poetics of everyday talk and performance that cuts across both 'high' and 'low' culture” (cf. 2007: 30-31).

In their volume on YouTube, Burgess together with Joshua Green moreover describe Vernacular Creativity as a feature of a participatory culture, where the process of creating becomes a social practice (2009: 26). They argue that the reason for uploading videos has just as much to do with engagement in social networking as it does with exhibitionism and self-promotion (ibid.). Although the creation of Mashups has a range of different purposes, according to Burgess and Green, it is noticeable how many Mashups are consumed within a shared community, thus articulating a mode of connectivity.

If we return to the Double Rainbow Song, it is a parodic music video: an autotune that mixes and transforms a home movie into a song. Double Rainbow Song is an example of vernacular creativity that is primarily a creative piece of work in the sense that it captures a core of humour that is shared with other YouTubers and that primarily makes sense within the YouTube community, where users obviously are familiar with the original clip. It thus takes on an anecdotal form and its noticeable commercial success on iTunes seems to be explained by this anecdotal form, which highlights social sharing and connectivity rather than artistic or aesthetic importance. This aspect of connectiv- 
ity is perhaps most noticeable in the video's intertextual references, which address the YouTube community members by expressing a collective voice that, in this case, ironically distances itself from the original clip. Double Rainbow Song turns a home video of an extravagant person into a creative work that has no traditionally acknowledged creative value; but it transforms the everydayness into a humoristic interpretation, and in that sense the autotune is an explicit case of Vernacular Creativity by sharing the funny anecdotes of everyday life. Its most important feature thus becomes its articulation of the community, which furthermore spreads the video through social platforms such as Twitter and Facebook.

\section{Collaborative Creativity}

Axel Bruns, following Henry Jenkins (2006) and Burgess and Green, advocates, with the emergence of social media, a change in the audiovisual distribution and production process of participation and user-driven activity. Along these lines, he stresses how a Mashup is defined by an ongoing creative process:

'Mashups': composite, multiply layered, and repeatedly reedited artworks, which in themselves remain also temporary artefacts of an ongoing creative process (2008: 235).

According to Bruns, a Mashup is also a co-creation, which is collaborative and involves not only the Mashup videos, but also the videos that surround them. This understanding of Mashups may well be illustrated in Ridley Scott's Life in a Day project or in a series of videos on YouTube, the Where do you YouTube series ${ }^{3}$. The series represents an ongoing creative process, in which users make a video response that links to the previous video, at the same time as the series imitates the style of the original video. Bruns states that many social media sites are inherently based on collaboration and sharing. The scale of individual creativity is therefore downgraded and replaced by collaborative creativity:

The collaborative aspects of produsage, in this and other cases: (...) the idea of the creative work, are substantially affected by community-based produsage efforts, as these undermine the idea of the work itself as a complete finished, and defined entity (2008: 231).

Thus, according to Bruns, collaborative creativity is an ongoing process rather than a finished work. Bruns exemplifies this with the photo collages of Flickr, the musicremixing site ccMixter and Wikipedia. While sites such as Wikipedia and Flickr perfectly demonstrate Bruns' perception of intentioned and explicit collective collaborations, it is necessary to raise the question of whether YouTube is also inherently defined by a collective creative voice. Is a video like Double Rainbow Song a collaborative work because it recombines already existing popular content on YouTube?

Double Rainbow Song exemplifies that a Mashup is arguably a collaborative piece of work in terms of the direct involvement of texts made by other creators, which provide the video with many voices, thus connecting people on YouTube. Double Rainbow Song is, nevertheless, only the source that leads to co-creativity, and the video itself is not a collective work made by many YouTubers. It is instead a fragment of popular culture available to be transformed into something new and simultaneously using an 
individual creative work to evoke and connect to other individual creative works (the video responses).

The understanding of creative collaboration in regards to the video therefore is not different across other media platforms. Books are published in collaboration with editors, films have production teams, and in this sense videos on YouTube are also collaborative. But the process of collecting material and transforming this material does not inherently involve a collective voice. Double Rainbow Song is the result of collaborative creativity, and the creator Schmoyoho is recombining already existing content, but the new meaning and change of genre (the transformation of a home movie into a satirical music video) are not the result of a collaborative process that is fundamentally different from other media creations, at least in terms of agency.

The mechanisms of Mashups on YouTube, it is argued, are different from other media platforms, but in terms of YouTube's implicit integration of social connectivity in accordance with the site's structural infrastructure. This aspect can fruitfully be elaborated on using Bolter and Grusin's concept of remediation.

\section{Mashups and Remediation}

Following the previous understanding of a Mashup as an audiovisual collage, Bolter and Grusin regard the collage as a historical example and specific type of what they have called "remediation" ("the representation of one medium in another", 1999: 45). YouTube Mashups likewise explicitly remediate film and television content. In regard to digital media, Bolter and Grusin argue that remediation could be experienced by the viewer manifested in an interconnected logic of two forms of remediation: "immediacy" as a transparent interface where the "user is not aware of confronting a medium" (ibid.: 24) and "hypermediacy" that seeks to depict the real by turning attention to its own construction (ibid.: 31). In the late 1990s, these terms were primarily used to refer to the logics of how the audience experienced the formal features of new media, either represented as an invisible style (exemplified by early virtual reality communities) or a fragmented distanced style (e.g., the read-only features of the early Internet). Overall, Bolter and Grusin described how digital media could be considered transparent while, at the time, reflecting on the construction of the medium itself.

The YouTube Mashups per se, in terms of style, are examples of hypermediacy, as they fragment and deconstruct different styles and texts, but they furthermore exhibit a mode of hypermediacy in terms of their emphasis on hyperlinks, which redirect attention towards the audiovisual construction while, simultaneously, serving to connect videos with other videos.

Richard Grusin has recently revisited the focus point of remediation, arguing that the double logic of remediation has changed somewhat accordance with the development of the Internet and the political situation, which he calls "premediation" (cf. Grusin 2009: 63). According to Grusin, contemporary examples of immediacy "materializes itself as an unconstrained connectivity so that one can access with no restrictions" (ibid.: 63), while hypermediacy is linked to the participation and distribution: "across multiple sociotechnical and mediated networks" (ibid.: 64). In that sense, Grusin turns the focus away from formal features towards the social and communicative features, which, however, involves YouTube's emphasis on hyperlinks. 
In regard to YouTube, Grusin sees the site as an example of the revisited logic behind remediation in terms of its distribution and logic of navigating through content:

YouTube provides perhaps the paradigmatic instance of this new media formation, insofar as its popularity is less a result of having provided users with new and better forms of media than of making available more mediation events, more easily shared and distributed (ibid.: 65).

Grusin implies that YouTube has not gained its widespread success due to specific forms of content or media devices, but due to its ability to connect and provide access to people. On YouTube, people navigate through hyperlinks and Video-On-Demand, and just as much new meaning is created in the paratextual contexts. The Mashups fit with this interchange of meaning, suggesting that rather than specific new forms of content, fundamental principles of accessibility and connectivity characterize the features of the YouTube Mashup. Immediacy on YouTube thus becomes the flow and communication about remediated content through hyperlinks, comments, ratings and video responding. In regard to YouTube, hypermediacy can be interpreted as a mental awareness of being visible, "leaving traces" (ibid.: 64) or being connected, in that YouTube is multi-functional, thus serving many co-existing functions embedded in various social networks. In that sense, the revisited approach to immediacy and hypermediacy is founded in the principles of connectivity that furthermore can be distinguished in the vacillation between collective user participation and individual self-expressions.

On YouTube, we can furthermore regard this connectivity as a double articulation that is registered in the social mechanisms of both sharing and promoting Mashups, but also in the infrastructure of YouTube, where videos are connected throughout links and meta-data. Mashups are produced within the accessibility and flow of YouTube content, and via the use of meta-data (the embedment of text signs, links, annotations) that draw attention to the construction of the videos as well as to the creator who uses connectivity to increase traffic in and around the video, thus creating visibility. This serves the purpose of socializing, but also of promotion - emphasizing that YouTube is fundamentally a commercial platform and has been since Google bought YouTube in 2006.

The Double Rainbow Song reveals this double articulation, on one level as a direct and primary commentator and distributor of the shared popular culture and social connectivity on YouTube, while it simultaneously draws attention to it's own construction by embedding annotations that serve both the purpose of connectivity and the purpose of promotion: the increase in traffic, links and the visibility of the creator. This can be illustrated by looking at the frame grab below of the screen of Double Rainbow Song, which involves several links (the arrows indicate examples of signs and links):

It is noticeable how the video uses links and signs to address social connectivity (primarily in terms of commercial promotion: "song on iTunes!", but also through the enablement of user comments below the video), while the video also demonstrates the basic principles of YouTube's link structure and interface, which further accentuates YouTube as a medium platform, i.e. watching a video on YouTube is not only about watching the video, it also about clicking on the several available links. In that sense, the Mashup demonstrates two modes of connectivity: one that emphasizes social connections, and one that emphasizes the structural features of the site - both with the same purpose of connecting the Mashups with the community of a shared popular culture. 
Figure 2. The Screen of Double Rainbow Song

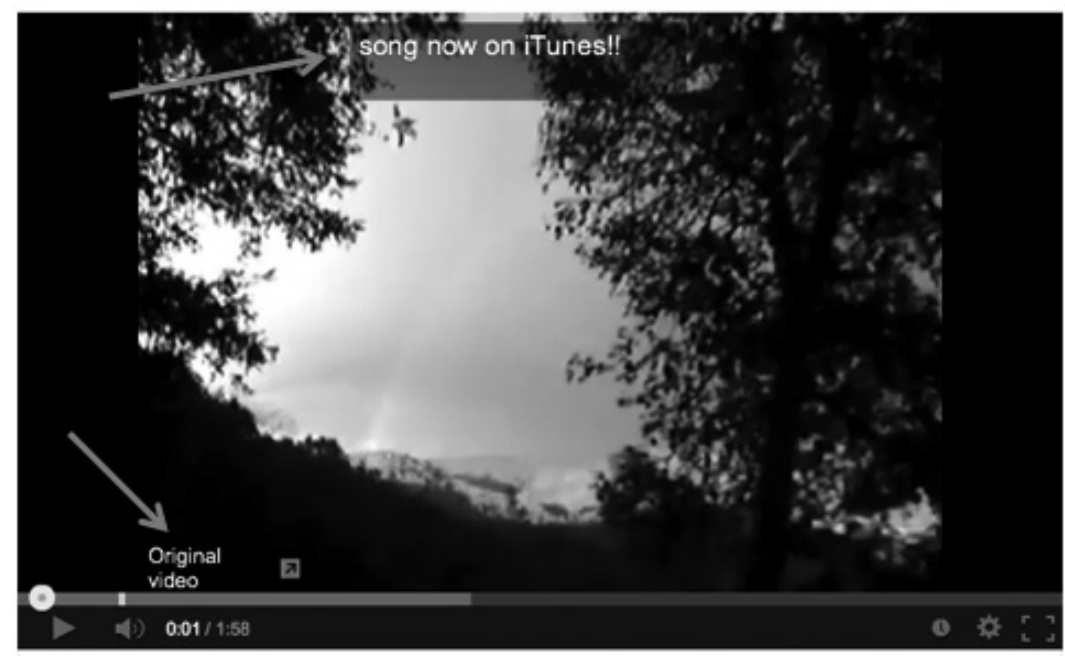

Songify This : DOUBLE RAINBOW SONG!! (now on ...

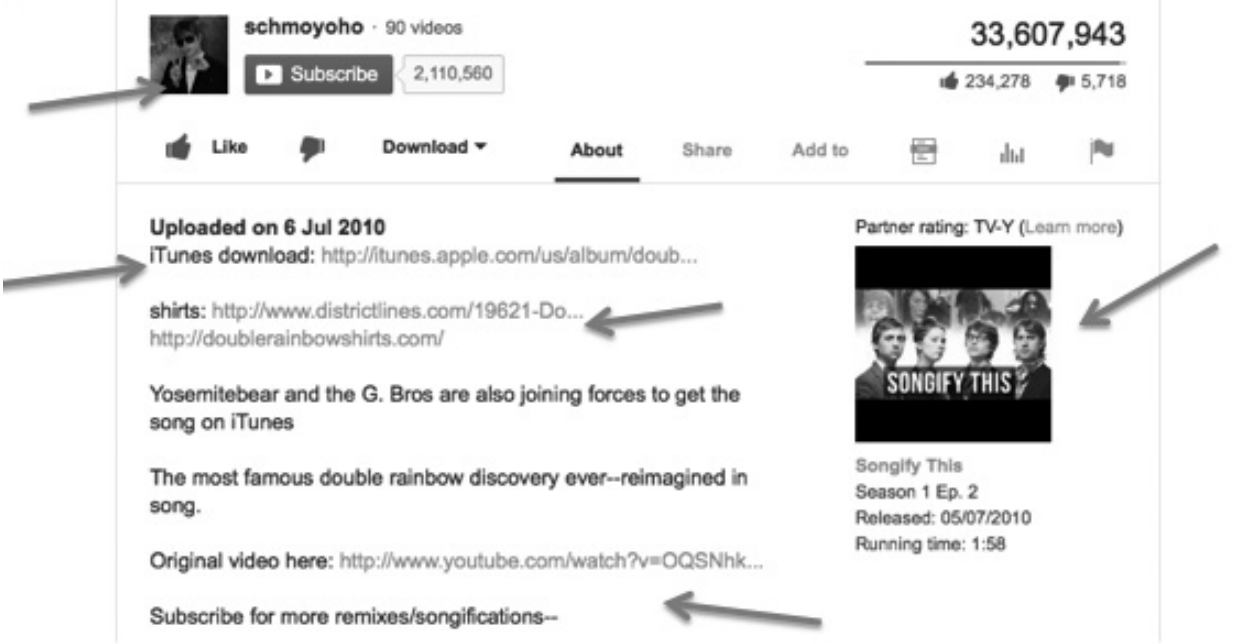

\section{Mashup Gaming Cultures}

In this last part of the article, I will elaborate on how the arguments made concerning the Mashups relate to the notion of connectivity by providing representative examples of Mashups taken from the aforementioned sample. The examples will furthermore illustrate the mechanisms of recontextualization. This also includes illustrations of the connectivity in the vacillation of user participation (and vernacular creativity) and individual self-expression.

One comprehensive way to create an overview of the Mashups is to identify what is being "mashup'ed". In this sample consisting of 92 videos, a majority of the videos can be identified as Mashups of computer games. Fifty-six (61\%) of the Mashup videos derive from computer games in the form of gaming commentary videos, game play 
music videos or narrative video told through the integration of computer games (often referred to as "Machinima"). Machinima is animated filmmaking using already existing gaming aesthetics. Mashups have emerged from the 1990s gameplay recordings of, e.g., Doom and Quake (cf. Hancock 2011). A Machinima is an independent narrative story told within the environment of an existing computer game. It resembles a traditional example of a creative work, and it emphasizes aesthetic and narrative skills less than social skills. Machinimas are, as mentioned earlier, dictated by an existing environment and pre-defined characters within the fictional world of the computer game. Machinimas are therefore typically playful and yet still respectful imitations of the specific game culture they remediate. But although distributed on the same channel, many of the Machinima creators regard themselves as individual creators either in terms of gaming skills or through their artistic expression, as underlined by Hugh Hancock in regards to Machinima: "The vast majority of Machinima created is clearly self-expression" (2011: 38). Gaming videos can therefore not solely be regarded within a collective creative process that is directly related to the existing environment.

The gaming videos also exemplify a shared space of creativity deriving from various different fan communities. Bruns, drawing on Jenkins, emphasizes fan communities as a key example of creative collaboration and participation (2008: 232). But the aspect of participation cannot solely explain the wide spread of gaming videos. The dominance of computer games perhaps also reflects that computer games are no longer a subculture, but are a part of mainstream culture. Another explanation is the fact that many computer games now enable recordings of user interactions and thereby provide users with a predefined style and an aesthetic that make the access to and creation of their own Mashups much easier.

Nineteen $(20 \%)$ of the videos in the sample are uploaded by the community channel Machinima and its sub-channel Machinimarespawn. The videos from Machinima are authorless, i.e. users who upload their videos directly to Machinima, which then becomes the collective voice of the video, produce the videos. In that sense, Machinima exemplifies the collaborative creativity discussed by Jenkins and Bruns. Here, creators establish a community in which they share their works and receive feedback, thus emphasizing social connectivity. The style and form of the gaming videos are hence dictated by the original computer games, where the creative process, in terms of narratives and aesthetics, is already designed by the original game (see also Diakopoulos et al. 2007). The new meaning created with the Mashup, however, depends on familiarity with the gaming environment, as also argued by Tracy Harwood: "Machinima (...) reflects the deeply embedded sociocultural context of the original games environment (...) Without knowing that context, it becomes difficult to make sense of the films, their qualities and content" (2011:7-8.pp.). In that sense, self-expression within the Machinimas is also tied to social connectivity.

\section{Socializing through Gaming Commentaries}

The sociocultural aspect is also demonstrated in the most frequent type of gaming videos in the sample. Thirty-three out of 56 gaming videos can be identified as gaming commentaries made by users, who through a voiceover explain and demonstrate their game skills while playing, e.g., Modern Warfare 2. The gaming commentaries are Mashups 
when they re-combine a computer game recording with a newly produced audio track that transforms the fictional gaming world into didactic and non-fictional reflections on gaming cultures that include both concrete gaming comments as well as everyday life reflections, contributing to the creation of new meaning beyond the basic gaming activity.

The Mashup Taylor Tuesday \#22 (...) ThatGoldenBullet12 exemplifies a transformation of a game into an everyday reflection. Two people, who we learn are a couple, intend to comment on a game play of Modern Warfare 2 that has been sent to them by another player. They, however, pay little attention to the game, which then becomes a peripheral visual reference. Instead the couple start a conversation on everyday topics, such as parenthood and pets, that has nothing to do with the game they are watching and intended to reflect upon. The video is thereby given a phatic function, communicating everyday reflections. In that sense, it becomes an example of Vernacular Creativity, more concerned with communicative practices than with the aesthetics of the game. The video is also collaborative in terms of its combination of commentaries and gameplay, but the collaboration is unbalanced, as the visual layer of the video is not given attention, and as argued, it only figures as background "noise". The explicit intention of the video is to give credit and acknowledge the gaming skills of the player ThatGoldenBullet12, but the video begins by criticizing the name of the player. ThatGoldenBullet 12 's player skills are thereafter given little attention, which is also evident in the written comments below, which rather respond to the dialogue between the couple.

While contributing to an online community, most of the gaming commentary videos are also self-promotional and associated with competitive activities, where the overall intention often seems to be a display of gaming skills. This is supported by the fact that the videos observed here only contain gaming videos with successful performances and impressive player scores (even though not all are recognized, e.g., Taylor Tuesday...). This shows how viewers favour videos that demonstrate the top gaming skills and that people only make videos of their best games. The videos thereby integrate and reflect on a competitive activity that is also related to the aspects of recognition and self-promotion overtly linked to the visibility and promotional strategies of the YouTube interface (cf. Simonsen 2011), demonstrating the co-existence of collective and individual expressions within a commercial context.

\section{Mashups as an Individual Expression}

One example of an individual creative work is Team Fortress 2 - Law Abiding Engineer. The video is an interesting demonstration of a Mashup that recombines the film medium with a computer game. The video imitates the trailer format, mixing already existing film footage from the original film trailer of the feature film Law Abiding Citizen with animated scenes inspired by the computer game Team Fortress 2. The complete audio track, i.e. a voiceover, from the original trailer is maintained, and in that sense the basic storyline does not change. But by integrating specific characters, the video only makes sense if viewers are familiar with the computer game and the specific characters and their relationship in the game, which thereby provides new meaning to the narrative.

Similar to other gaming Mashups, Team Fortress 2 - Law Abiding Engineer accordingly communicates within a fan community specifically related to the game. However, in contrast to, e.g., gaming commentaries, Team Fortress 2 - Law Abiding Engineer, 
Figure 3 \& 4. Team Fortress 2 - Law Abiding Engineer
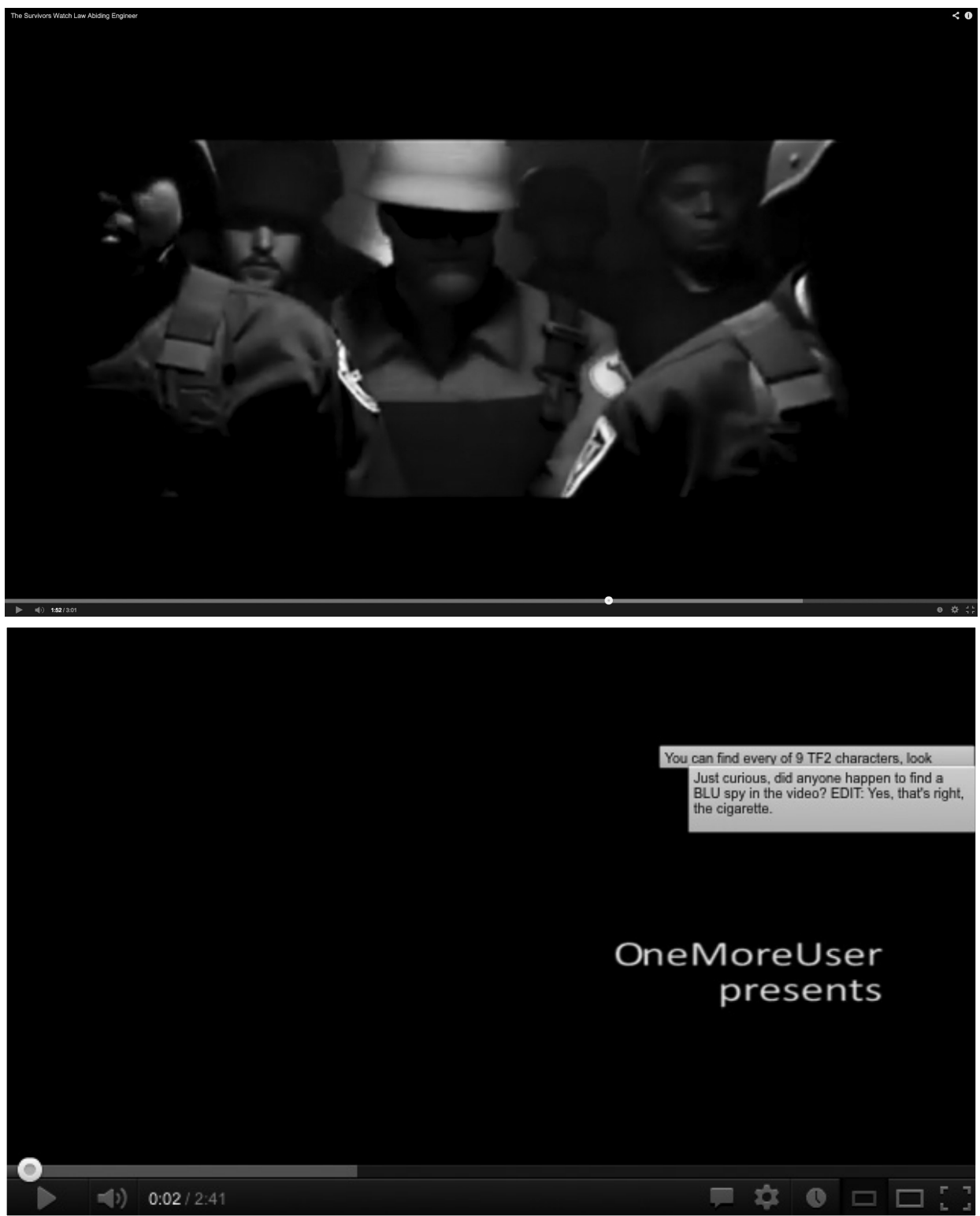

when originally uploaded, did not call for community participation, but rather for skilful acknowledgement, as TrueOneMoreUser underlines by placing himself in the intro-credits as director and by declaring in the text below the video: "I proudly present my biggest animating/compositing project I ever did." The majority of comments are also accolades to the creator's visual and editing skills rather than comments related to the universe of the game or the everyday reflections. But TrueOneMoreUser has subsequently added text signs that address the YouTube community regarding the computer game characters encouraging them to socialize throughout, as can be seen in Figure 4, e.g.: "just curious, did anyone happen to find a BLU spy in the video?". By adding these 
signs with questions, users are encouraged to reflect on the video, turning the signs into meta-data that also draw attention to YouTube as a specific medium platform. The signs are thus illustrations of the inherent double articulation of connectivity that includes socialization, but also hypermediacy by using meta-data, which as an extra graphic layer interferes with the original image of the video.

\section{Mashups of Popular Culture}

In the sample, there are also several Mashups that derive from the more widespread popular culture. These references account for film references (160 Greatest Arnold Schwarzenegger Quotes or The 100 Greatest Movie Insults of All Time), popular music Mashups ("Overboard - Justin Bieber" and HOT K-POP 2010), sports collages (Press Hop 2, Gracias Raul!) and animé and cartoons (TFS Episode 14). As mentioned earlier, this also includes Mashups that remix content deriving from the popular sphere of YouTube.

Many videos recombine the more widespread popular culture, which positions the videos either with an ironic distance or with an acknowledgement of the original content. The predominant group of Mashups belongs to the latter group, where many videos can be considered homages and celebrations of popular culture. They also resemble the mundane of the bricolage style when they collect all available clips of pop-stars. This group includes videos such as Justin Bieber Pray music video Eenie Meenie Love Me (...) and ;Gracias, Raúl!. Such videos are celebrations of stars from the larger sphere of popular culture. They can be regarded as audiovisual illustrations similar to a teenage bedroom, with decorations of pop-stars moving out of the private sphere and into the public space of YouTube.

Figure 5. Justin Bieber Pray Music Video Eenie Meenie Love Me..."

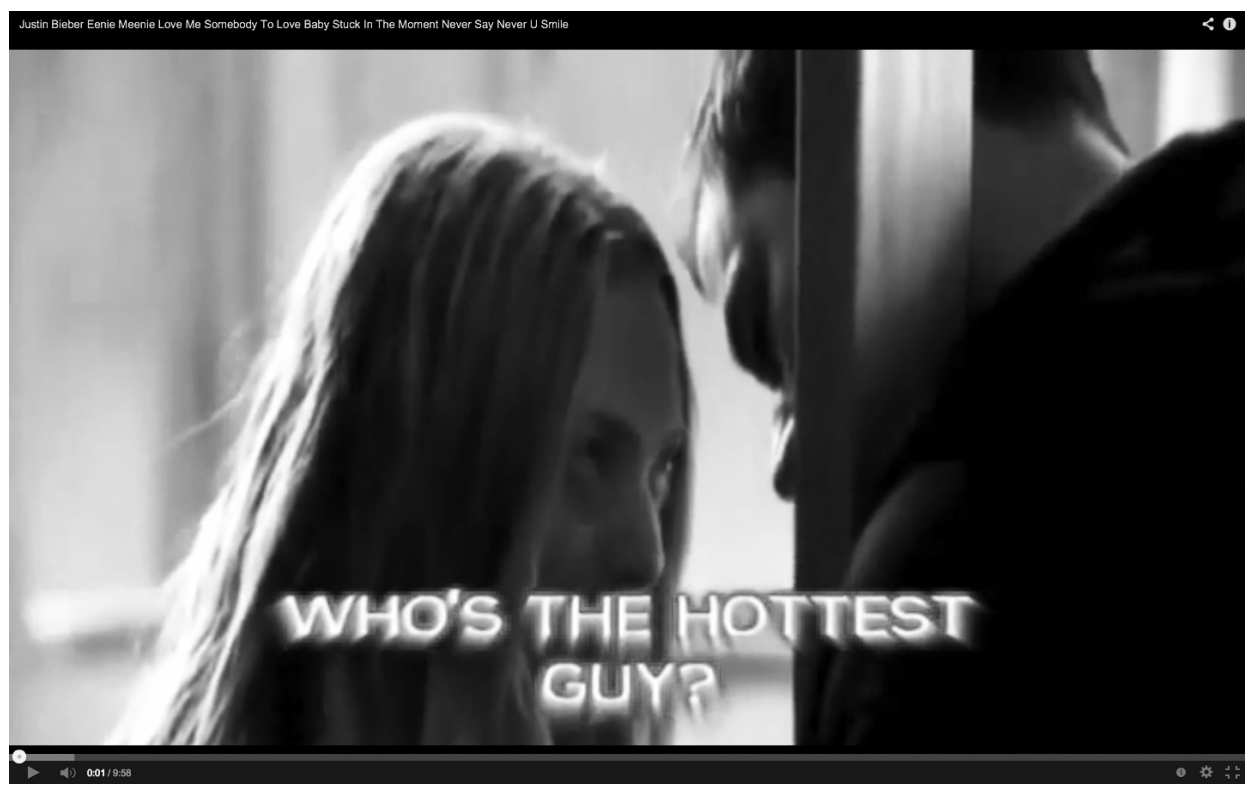

Justin Bieber Pray music video Eenie Meenie Love Me (...) is a musical collage that reflects on popular culture. It calls for social interaction by adding a text in the beginning 
of the video, asking: Who's the hottest guy? The dialogic emphasis is further underlined in the related text describing the video below, where users are asked: "who is the hottie you like most! please tell me i curious! luvs!". The video is created within a community of Justin Bieber fans who communicate and share knowledge about their idol by making videos referring to Bieber. Much like the gaming videos, the fan homages are active parts of a fan community, although it is less homogenous and does not require specific knowledge, making it easier to access the community of popular culture.

Justin Bieber Pray music video Eenie Meenie Love Me (...) illustrates how the Mashup can be used to generate connectivity with other users in terms of judgment, cultural taste and socializing contributions, where one aspect of making these videos seems to be to strengthen social bonds and responses among community members. The video does so by turning the everydayness of photos of teenage idols into a creative expression that people can gather around and engage with. It is thereby an illustration of Vernacular Creativity, serving a communicative purpose through the sharing of popular culture. At the same time, however, the video is also an individual creative expression showing the skill of combining pictures with music that is thus concerned with social recognition, but also implicitly with striving for visibility through an increase in traffic data, which the videos achieve through large numbers of comments related to the video, and where the signs, as in the case of Team Fortress 2, add a reflexive layer to the video.

What the above-mentioned examples all have in common is that the new meaning they create is connected to well-known cultural phenomena including: Justin Bieber, Modern Warfare, Team Fortress, sports stars as well as the original Double Rainbow video (35 million views). This indicates that the visibility and popularity of Mashups, within this sample, are closely connected to and rely on the popularity of the source being Mashuped.

\section{The Double Articulation of Connectivity}

On the one hand, the Mashups referred to here serve a communicative and socializing purpose by referring to a shared mainstream community that can be explicitly collaborative (Taylor Tuesday..., Justin Bieber...) or more implicitly collaborative through intertextual references (Team Fortress 2 - Law Abiding Engineer). On the other hand, there is simultaneously an awareness of the community as a commercial space, which leads to a pursuit of visibility, where subscriptions and viewings count beyond social purposes and leave traces both of the video as well as the creator. For instance, in Taylor Tuesday..., the creator of the video, besides having social purposes, also links to sponsors and encourages users to subscribe through screen tags.

These aspects reveal a two-fold understanding of the YouTube Mashup as an example of social connectivity that also ties in to Grusin's revisited understanding of remediation in relation to connectivity and articulates the double logic of remediation. In terms of immediacy: by highlighting YouTube as a homogenous community built on the collective sharing of e.g. popular culture. In terms of hypermediacy: by highlighting individual self-promotion. Different levels of participation and consumption, and different modes of motivation for creating, turn our attention towards the fact that the new meaning Mashups provide does not necessarily connect people in the same way, underlying how connectivity serves the purpose of individuality. This is perhaps best underlined in Team 
Fortress 2 - Law Abiding Engineer, through the individual creator and in the comments below the video, which reveal an ongoing discussion of the characters in the computer game aimed at a specific and initiated community of gamers, while others clearly have no knowledge of the game and are instead focusing on the cinematic trailer format.

In regard to structural connectivity, YouTube as a media platform further creates a sense of immediacy through folksonomies, tags and links that are shared among the viewers, which they furthermore use to navigate through and make sense of the site. This also includes comments that allow viewers to verify a specific video, just like texts signs can serve the purpose of exchanging information and meaning flawlessly across different channels. Most of the Mashups observed in the sample integrate possible links within the video, and the link structure is moreover highlighted on the Mashups' respective channels, as can be seen with the links embedded on the Machinima channel:

Figure 6. Links on Machinima YouTube Channel

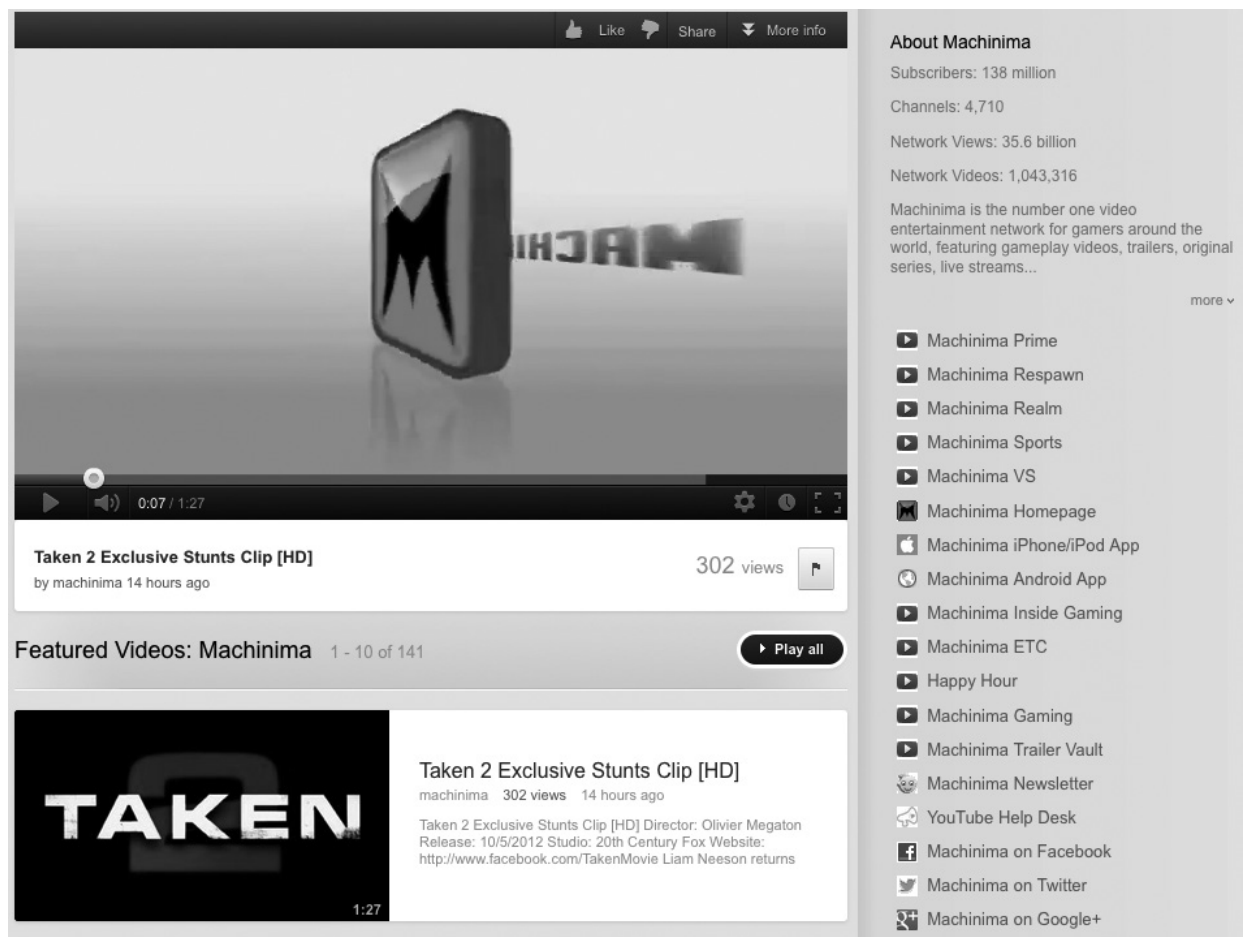

Figure 6 shows how a video is presented along with a large list of links to several different channels or apps with different functions, such as Facebook, Twitter, that furthermore include other types of media tools (mobile phones and iPods). In that sense, Machinima enables a fundament for structural connectivity on various platforms, where the channel thus becomes a Mashup of data and software - embedding several media and social media platforms within the YouTube channel. The infrastructure of both videos and channels on YouTube thus go hand in hand with the process of recontextualization. Although the linking structure is, of course, not limited to Mashups on YouTube, the structure helps visualize how users can implicitly navigate through videos, following 
the very same principles of the bricolage as an everyday mode of communication, where users make sense through audiovisuality being remixed. In that sense, the coexistence of social and structural principles of the YouTube Mashup can be regarded as an everyday and medium-specific mode of communication.

\section{Conclusion}

The present article has investigated a limited spectrum of the Mashups on YouTube in order to provide an understanding of how they serve as a specific mode of communication, producing new meaning, social bonds as well as self-promotion, while simultaneously serving as an exponent of YouTube's structural organization.

Mashups have been introduced as audiovisual texts that follow the principles of collage and bricolage, but they are also adjusted to the accessibility of YouTube, enabling the transformation of specific production of content and gaining their success through social and communicative features.

The article has attempted to demonstrate that the YouTube Mashup ranges from different approaches and understandings of YouTube that may share the foundation of a social community fostering co-creativity and collaboration, but in accordance with YouTube's gradual transformation into a commercially defined media platform, the premises for production are equally changing, making the collective creative voices into potential commodities. The Mashup must therefore be understood as inevitably enrolled in this context, where the user-defined collaborative community coexists with aspiring artistic expressions founded in the fundamental act of self-promotion.

The article has also tried to demonstrate that the novelty and popularity of the YouTube Mashup is not to be found in its formal or aesthetic characteristic. It should rather be found in its ability to turn ordinary everyday activities into social and cultural value that is consumed and promoted within the YouTube community as a mode of connectivity - addressing a shared popular culture.

Connectivity has been regarded as a double articulation of the social events taking place in and around the film, but also in terms of YouTube's infrastructure, which organizes the content in a way that stresses a mode of structural connectivity. This has been elaborated on by further applying the notion of remediation to a distinction between the logic of immediacy, as social connectivity within the YouTube community, and hypermediacy, as a description of the divergence and multi-functionality of connectivity. The principles of the YouTube Mashups have been exemplified through various examples taken from an empirical study of YouTube content, where different examples of Mashups have demonstrated aspects of social connectivity in terms of collective co-creation, but also as a mode of self-promotion distributed through connectivity that is also linked to the structural connectivity of YouTube's interface, where especially the video Double Rainbow has demonstrated this double articulation of connectivity.

In conclusion, the article has presented the YouTube Mashups as a medium-specific mode of communication that illustrates how the flow and accessibility of remixed content has enabled a culture based on audiovisual recontextualization, and how the diversity of digital audiovisual communication constantly changes according to the dynamic coexistence between social and structural connectivity on YouTube. 


\section{Notes}

1. Cf. YouTube-global blog.com: / http://youtube-global.blogspot.dk/2012/01/holy-nyans-60-hours-perminute-and-4.html. Retrieved, September 10, 2012.

2. See link: http://knowyourmeme.com/memes/double-rainbow\#fn2

3. These videos are analysed in detail by Adami (2009) 'We/YouTube': Exploring sign-making in videointeraction.

\section{References}

Bolter, J. \& R. Grusin (1999) Remediation, Understanding new media. Cambridge, Massachusetts: The MIT Press.

Bruns, A. (2008) Blogs, Wikipedia, Second Life and Beyond: From Production to Produsage. New York: Peter Lang Publishing.

Burges, J. (2007) Vernacular Creativity and New Media, Ph.D. Dissertation, Queensland University of Technology,

Burgess, J. and J. Green (2009) YouTube, Online Video and Participatory Culture. Cambridge: Polity Press. Diakopolus, N. et al (2007) Remixing Authorship. Georgia Institute of Technology.

Grusin, R. (2009) YouTube at the End of New Media. In P. Snickars \& P. Vonderau (eds.). The YouTube Reader. Stockholm: National Library of Sweden.

Hancock, H. (2011) Machinima: Limited, Ghettoized, and Spectacularly Promising. In Journal of Visual Culture 2011, 10 (1), 31-37.

Harwood, T. (2011) Towards a Manifesto for Machinima. In Journal of Visual Culture 2011, 10 (1), 6-12.

Hawkes, T. (2003/1977) Structuralism and Semiotics. London: Routledge.

Hebdige, D. (1979) Subculture: Meaning of Style. London: Routledge.

Jenkins, H. (2006) Convergence Culture, New York: N.Y. University Press.

Katz, M. (2010) Capturing Sound. Berkeley: University of California Press.

Keen, A. (2007) The Cult of the amateur. New York: Doubleday.

Leví-Strauss, C. (1966) The Savage Mind. Chicago: The University of Chicago Press.

Manovich, L. (2007) What comes after Remix? On Remixtheory.net. Retrieved August 2012: http://remixtheory.net/? $\mathrm{p}=169$

Michelson, A. (1984) Kino-eye: the writings of Dziga Vertov. Berkeley: University of California Press.

Miller, P. et al (2008) Sound unbound, Sampling digital music and Culture. Cambridge Massachusetts: the MIT Press.

Simonsen, T. M. (2011) Categorizing YouTube. In MedieKultur Vol. 28, No. 51, 72-93

Strangelove, M. (2010) Watching YouTube, Toronto: University of Toronto Press.

Uricchio, W. (2009) The Future of a Medium Once Known as Television. In P. Snickars \& P. Vonderau (eds.). The YouTube Reader. Stockholm: National Library of Sweden.

THOMAS MOSEBO SIMONSEN, Ph.D., Assistant Professor, Department of Communication and Psychology, Aalborg University, tms@hum.aau.dk 